\title{
FEA and Optimization of Flywheel Energy Storage System
}

\author{
Aakash B Rajan ${ }^{1}$, Parth H Patel ${ }^{2}$, Dr. Tushar M Patel ${ }^{3}$ \\ ${ }^{1}$ M.E. Scholar, Mechanical Engineering Department, LDRP-ITR, Gandhinagar, India \\ ${ }^{2}$ Assistant Professor, Mechanical Engineering Department, LDRP-ITR, Gandhinagar, India \\ ${ }^{3}$ Professor, Mechanical Engineering Department, LDRP-ITR, Gandhinagar, India
}

\begin{abstract}
The objective of this Paper is to carry out a case study in finding an optimal combination of design, material designation and geometry modification of the flywheel which results in increasing the overall energy storing capacity of the flywheel. The geometrical design of the flywheel and the material of the flywheel are the considered variables here. Optimum flywheel is chosen on the basis of weight, energy density, energy storing capacity and specific energy of the flywheel. Considering the amount of variables and results, for better selection of the flywheel design a (DOE) Design of Experiments is chosen along with using Finite Element Analysis. Using both these approaches the best possible flywheel is obtained for better energy storage.
\end{abstract}

Keywords: Increasing energy, parametric optimization, Flywheel, FE Analysis, FEA-Design, Energy Density, Material characterization, Taguchi Method

\section{Introduction}

Essentially a flywheel is a heavy wheel that needs some force to start it spinning. It might be a largediameter wheel with spokes and a very heavy metal rim, or it could be a smaller-diameter cylinder made of something like a carbon-fiber composite. Either way, it is a kind a wheel that needs huge amount of force to spin as well as to stop its spin. Which means that it tends to keep on spinning even if the force applied is removed. This rotation of the flywheel tends to store the energy in the form of kinetic energy. The energy storing capacity can be further optimized by proper selection of geometry, design and material.

The main objective of the research is to increase the storing capacity of flywheel in terms of energy. The energy stored in flywheel depends on the density, type of flywheel and its geometry. Hence to increase the energy capacity, several materials and designs are chosen for the selection of better flywheel. This is done by theoretical values as well as using FEA. Several parameters are considered and to reduce the time consumption, Design of Experiment is used.

\section{Literature Review}

Many scientists and researchers have carried out some work in this direction. Some of which have considered using analytical techniques for better computation. BAI et al. (2008) proposed a method to design a flywheel rotor composed of composite rim and a metal hub by studying the connection between the rotor and the driving machine. Analysis is done on the influence of some factors such as the rotor material, configuration, fracture techniques and connection on energy density. Optimization of the hub can improve the energy density efficiently. The testing results match with the emulation results, hence proving that the design method is useful [1]. TANG et al. (2012) the auxiliary support was removed until the flywheel passed the first critical speed. The flywheel is kept at rigid state in sub critical condition and tested at high speed. Discussed the lower damper's effect on the modal damping ratios and forced vibrations. The sub critical rotor dynamics design and pivot jewel bearing to be good solutions to the spin test for the composite flywheel [2]. YU et al. (2012) proposed novel flywheel energy storage for marine systems. The purpose was to improve the power quality of a marine power system (MPS) and strengthen the energy recycle. The electrical machine electromagnetism design was further optimized by the FEA in the temperature field, to find the local overheating point under the normal operation condition and provide guidance for the cooling system. Finally, it can be concluded from the comprehensive physical field analysis that the novel redundant structure M/G can improve the efficiency of the M/G and maintain the stability of the MPS [3]. PIETRASZEK et al. (2012) presented to automotive industry optimization problem the fuzzy regression approach. They summarized problem definition, measured data presentation and analysis of the final with classical and fuzzy regression approach. He also shows the benefit of fuzzy regression approach [4]. PATEL et. al. (2013) used FEA and analysis to validate chassis frame of Eicher 11.10 and calculated stress and deformation to obtain the best solution for chassis frame [5]. ESFAHANIAN et al. (2013) presented designing, modelling and simulation of three hybrid power trains. Presented based on power requirements the design process for each hybrid power train. Implementing the components efficiency in each powertrain is the most important stage in modelling process. The results indicated that the electric hybrid powertrain has the most effect on the reduction of fuel consumption. The hydraulic hybrid power train is 
recommended regarding the fabrication expenses and manufacturing complexity [6]. JIANG et al. (2014) established a flywheel rotor system for design flexibility. Analyzed the force of PMB through FEM and verified experimentally. Introduced a squeeze film damper to support bottom rolling bearing, enhance stability of the rotor system and suppress lateral vibration. They showed that the flexibility design and hybrid bearing for the system allow for the use of a small rolling bearing to reduce power loss [7]. WEN ET el. (2014) obtained the stress analysis of anisotropic flywheel rotor under high speed rotation. They derived maximum radial stress location equation by Newton Iteration Method. They studied the effects of flywheel anisotropy degree and the symmetricity of the maximum radial stress location [8]. ARAKELIAN et al. (2014) discussed development of reactionless planar parallel manipulators that applies no reaction moments or forces to mounting base during motion. Proposed design equations and technique that allow dynamic substitution of moving platform by three concentrated masses. A weightless link with three concentrated masses is represented by dynamic model of moving platform. They verified that manipulators are reactionless through computer simulations and results [9]. HAMZAOUI et al. (2016) presented two techniques of commands to apply in the system of converting wind energy into storage. The energy storage system based is associated with the wind generator. To receive a faster response, the direct control of the systems eliminates the block of pulse with loops of regulations and width modulation. The simulation results are developed in Matlab of the model of the complete system [10]. RUPP et al. (2016) analyzed the introduction of flywheel energy storage systems in a light rail transit train. Mathematical models of the train, driving cycle and flywheel energy storage system are developed. Results suggest that maximum energy savings of $31 \%$ can be achieved using flywheel energy storage systems. The introduction of flywheel energy storage systems in a light rail transit train can therefore result in substantial energy and cost savings [11].

\section{Material Of Model}

The material considered for the computation of flywheel energy are Grey Cast Iron, Carbon Steel and Aluminum Alloy. The material properties are as shown in table 1.

Table 1: Material Properties of Flywheel [7]

\begin{tabular}{|c|c|c|c|}
\hline Material & Grey Cast Iron & Carbon Steel & Aluminium Alloy \\
\hline Density, $\mathrm{kg} / \mathrm{m}^{3}$ & 7200 & 7850 & 2770 \\
\hline Yield Strength $(\mathrm{MPa})$ & 240 & 250 & 280 \\
\hline Ultimate Strength $(\mathrm{MPa})$ & 276 & 460 & 310 \\
\hline Poisson's Ratio & 0.28 & 0.3 & 0.33 \\
\hline
\end{tabular}

\section{Methodology}

To start up the process of better selection of flywheel design and material allocation, it is necessary to follow a certain procedure. The parameters needed for the analysis are selected and their properties and effects on the experiments are taken into consideration. The FEA is carried out on the various combinations of the variables available and the results are analyzed.

Design Process:

- Definition of problem

- Determine the output most critical to the present problem

- Selection of variables and parameters

- Creating a mathematical model

- Perform analysis on the various sets of variables at disposal

- Statistical analysis and interpretation of experimental results.

- Final combination of finite analysis and theoretical data for validation Flow chart of the experiment is given in figure 1.

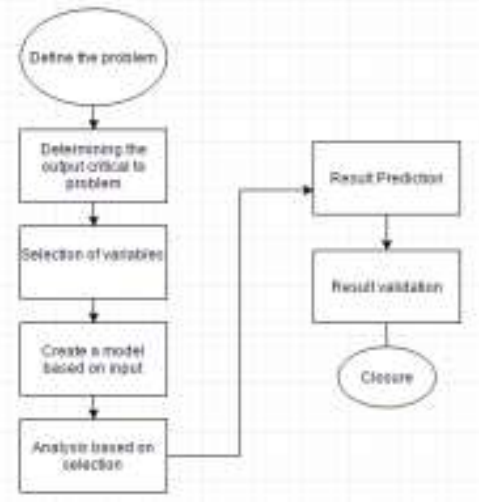

Fig. 1: Design Process 


\section{Analytical Method}

Analytical calculations are carried out for the various set of parameters available for the optimum selection of the flywheel. The calculations are carried out on the basis of following formulas governing the operation of flywheel. The amount of energy that can safely be stored in the rotor depends on the point at which the rotor will warp or shatter. The hoop stress that develop within the rotor is a major consideration in the design of a flywheel energy storage system.

- $\quad \mathrm{s}_{\mathrm{t}}=\rho \mathrm{r}^{2} \mathrm{w}^{2}$

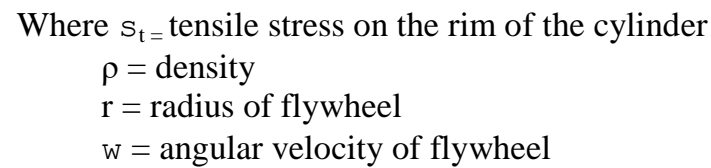

There are certain parameters governing the design and the process of optimizing the energy capacity of a flywheel such as geometry, material and its density.

Various fundamental equations that can help in deciding the required criteria are

Angular Velocity $(\mathrm{w})=(2 \pi \mathrm{N}) / 60 \mathrm{rad} / \mathrm{sec}$, Surface Speed $\left(\mathrm{V}_{\mathrm{s}}\right)=(\pi \mathrm{DN}) / 60 \mathrm{~m} / \mathrm{s}$,

Energy Stored in flywheel $\left(\mathrm{E}_{\mathrm{k}}\right)=0.5 \mathrm{I}_{\text {total }} \mathrm{w}^{2} \mathrm{KJ}$ [12]

The results are formulated in the table given below for different combination of available variables.

Table 2: Experimental Results Table

\begin{tabular}{|c|c|c|c|}
\hline Geometry & Material & $\begin{array}{c}\text { Kinetic Energy } \\
(\mathbf{K J})\end{array}$ & Weight (Kg) \\
\hline Perforated & Grey Cast Iron & 44 & 1130 \\
\hline Perforated & Carbon Steel & 48 & 1230 \\
\hline Perforated & Aluminium Alloy & 17 & 435 \\
\hline Solid & Grey Cast Iron & 45 & 1155 \\
\hline Solid & Carbon Steel & 49 & 1260 \\
\hline Solid & Aluminium Alloy & 17 & 445 \\
\hline Arm Type & Grey Cast Iron & 40 & 1032 \\
\hline Arm Type & Carbon Steel & 44 & 1126 \\
\hline Arm Type & Aluminium Alloy & 15 & 398 \\
\hline
\end{tabular}

\section{Result And Discussion}

The experiments result table gives a clear idea on what are effects of the design and material selection on the operation of flywheel. The weight of the flywheel are calculated as per weight=mass ("') in a modelling software after designing all three forms of design of flywheel and assigning material to them as per the table above. It can be seen that the lowest weight is of arm type flywheel when assigned carbon steel to it and heaviest is the solid flywheel with the same material. Hence it can be said that the material selection has less impact when the geometry is taken into account.

\subsection{Analysis for Perforated Flywheel}

The analysis is carried out for perforated flywheel by continuously changing the assigned material that is carbon steel, cast iron and aluminum alloy. The analysis is done to find the equivalent Von-Mises stress and total deformation for different materials and static condition. The resultant values are shown in figure.
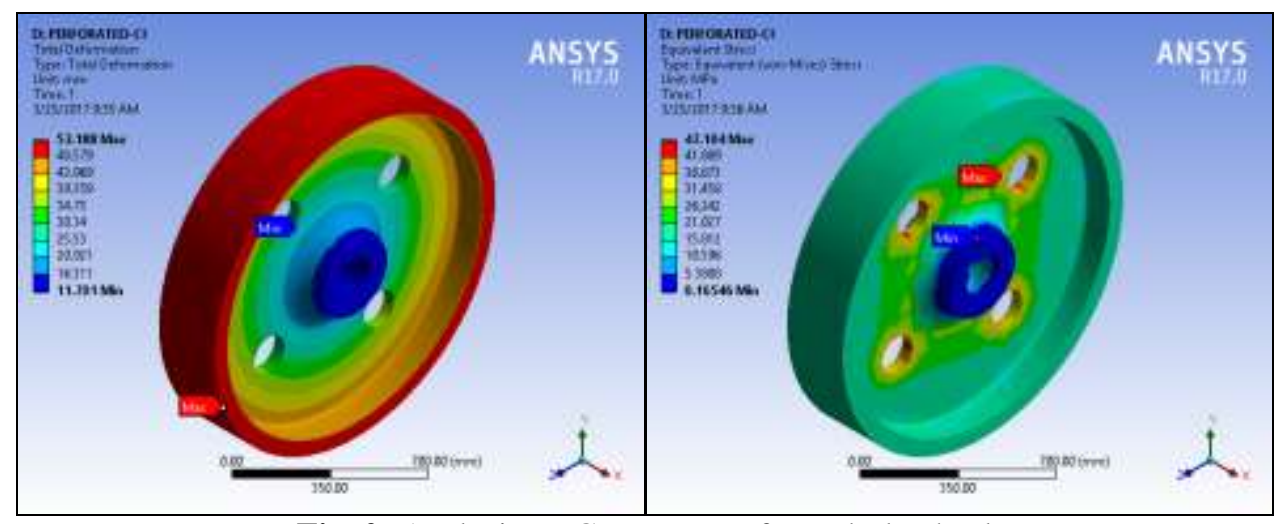

Fig. 2: Analysis on Cast Iron Perforated Flywheel

The resultant equivalent Von-Mises stress is $47.10 \mathrm{MPa}$ and total deformation is $53.18 \mathrm{~mm}$. 


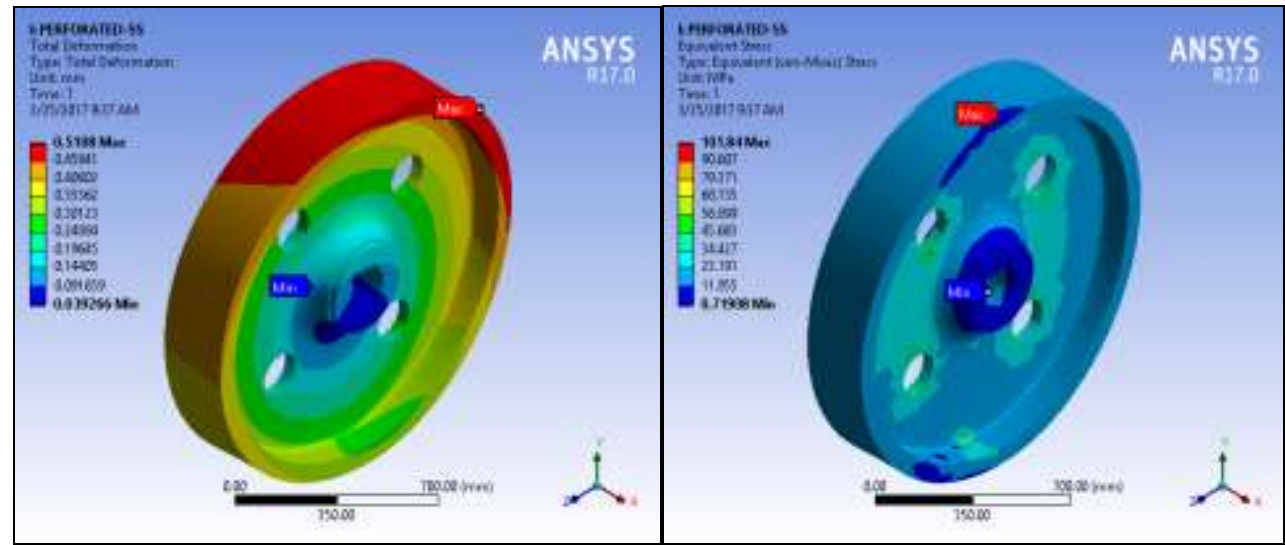

Fig. 3: Analysis on Carbon Steel Perforated Flywheel

The resultant equivalent Von-Mises stress is $101.84 \mathrm{MPa}$ and total deformation is $0.51 \mathrm{~mm}$.

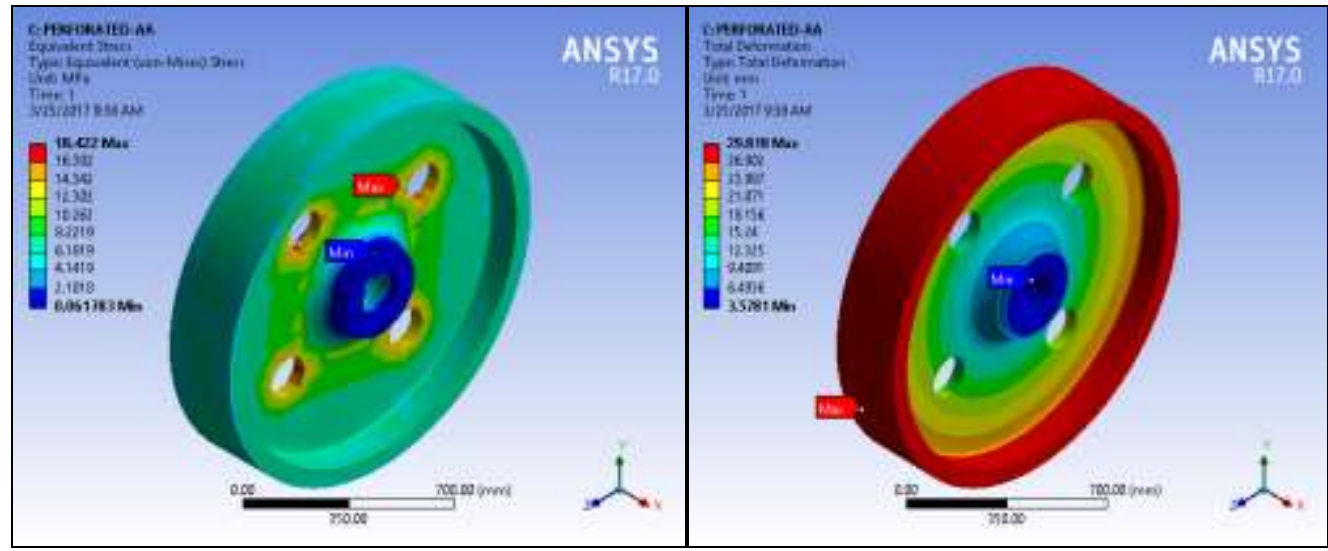

Fig. 4: Analysis on Aluminum Alloy Perforated Flywheel

The resultant equivalent Von-Mises stress is $29.81 \mathrm{MPa}$ and total deformation is $18.42 \mathrm{~mm}$.

\subsection{Analysis for Solid Flywheel}

The analysis is carried out for solid flywheel by continuously changing the assigned material that is carbon steel, cast iron and aluminum alloy. The analysis is done to find the equivalent Von-Mises stress and total deformation for different materials and static condition. The resultant values are shown in figure.

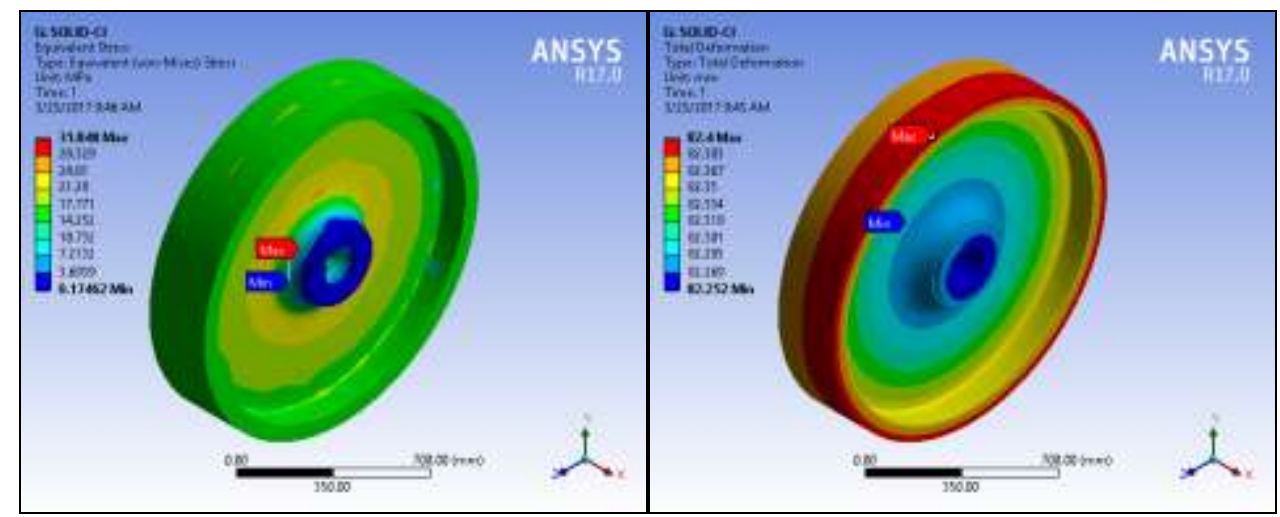

Fig. 5: Analysis on Cast Iron Solid Flywheel

The resultant equivalent Von-Mises stress is $82.4 \mathrm{MPa}$ and total deformation is $31.84 \mathrm{~mm}$. 


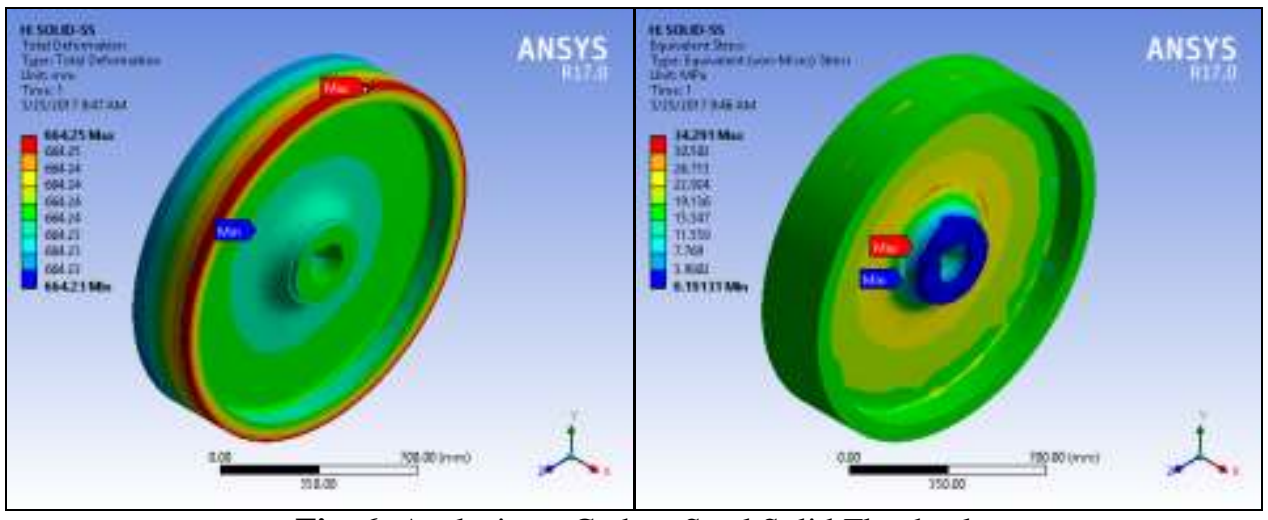

Fig. 6: Analysis on Carbon Steel Solid Flywheel

The resultant equivalent Von-Mises stress is $34.29 \mathrm{MPa}$ and total deformation is $664.25 \mathrm{~mm}$.

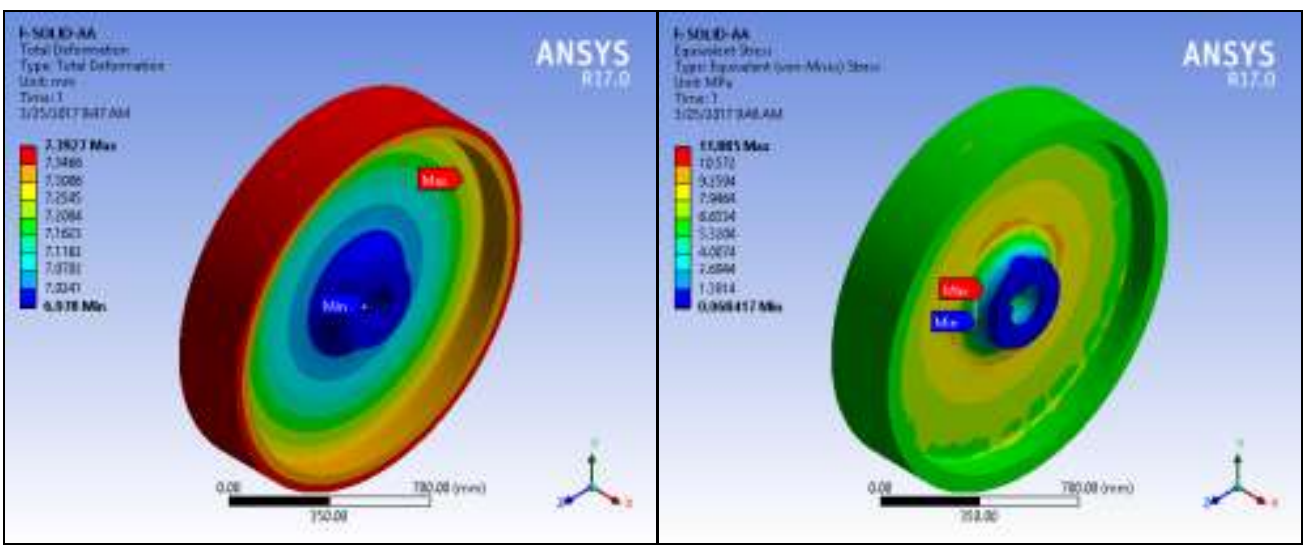

Fig. 7: Analysis on Aluminum Alloy Solid Flywheel

The resultant equivalent Von-Mises stress is $11.88 \mathrm{MPa}$ and total deformation is $7.39 \mathrm{~mm}$.

\subsection{Analysis for Arm Type Flywheel}

The analysis is carried out for arm type flywheel by continuously changing the assigned material that is carbon steel, cast iron and aluminum alloy. The analysis is done to find the equivalent Von-Mises stress and total deformation for different materials and static condition. The resultant values are shown in figure.

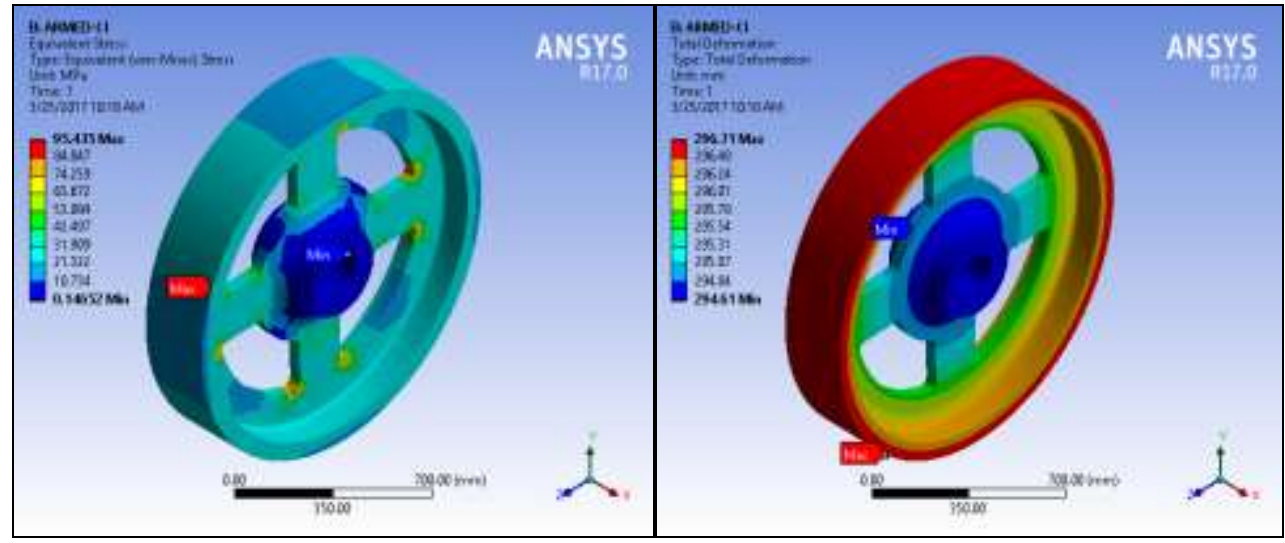

Fig. 8: Analysis on Cast Iron Arm Type Flywheel

The resultant equivalent Von-Mises stress is $296.71 \mathrm{MPa}$ and total deformation is $95.43 \mathrm{~mm}$. 


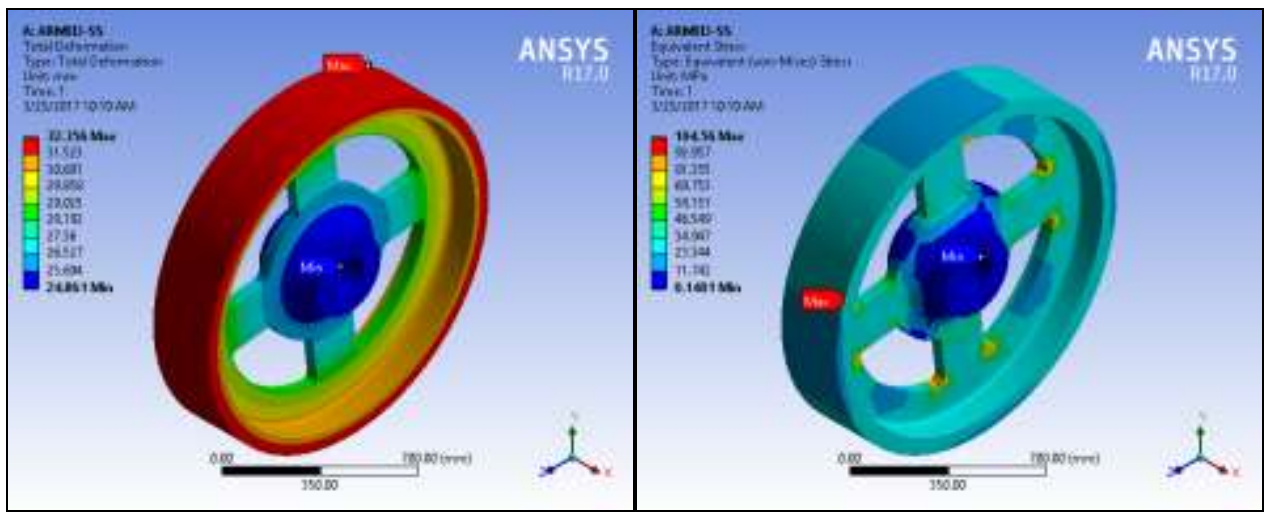

Fig. 9: Analysis on Carbon Steel Arm Type Flywheel

The resultant equivalent Von-Mises stress is $104.56 \mathrm{MPa}$ and total deformation is $32.35 \mathrm{~mm}$.
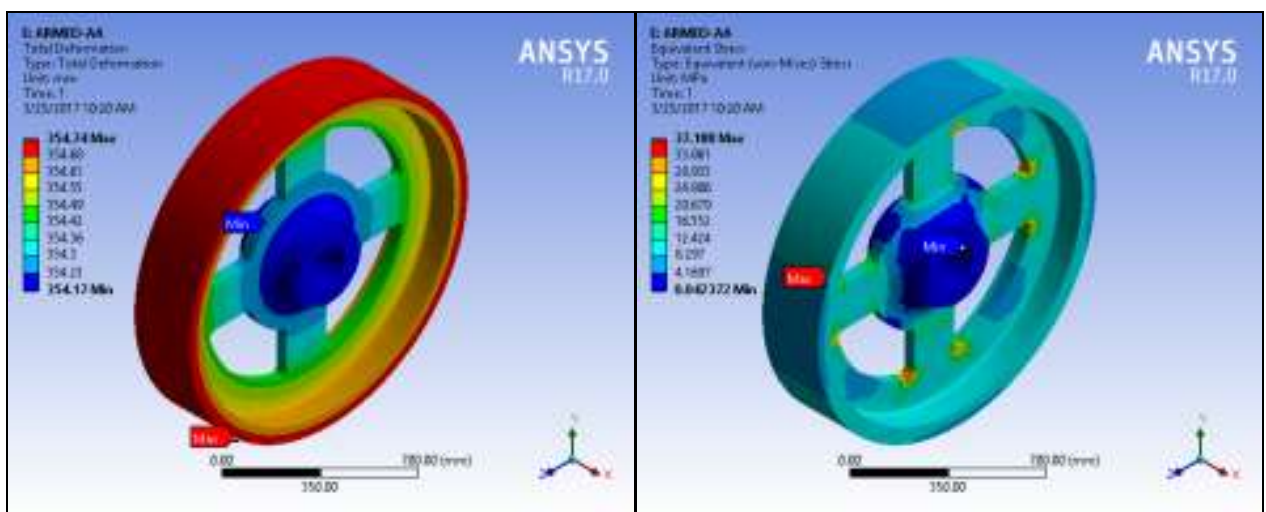

Fig. 10: Analysis on Aluminum Alloy Arm Type Flywheel

The resultant equivalent Von-Mises stress is $37.18 \mathrm{MPa}$ and total deformation is $354.74 \mathrm{~mm}$, taking into account the various results obtained from the analysis, we can say that the best possible design and material combination set is that of the perforated flywheel with carbon steel as the assigned material. The obtained results are further validated by theoretical value in the subsequent chapter.

\section{Validation Of Result}

The analytical data is compared with the theoretical data of stress by the stress formula as $\mathrm{s}_{\mathrm{t}}={\rho r^{2}}^{2} \mathrm{w}^{2}$

Where $s_{t}=$ tensile stress on the rim of the cylinder

$$
\begin{aligned}
& \rho=\text { density } \\
& r=\text { radius of flywheel } \\
& w=\text { angular velocity of flywheel }
\end{aligned}
$$

Table 2: Experimental Results Table

\begin{tabular}{|c|c|c|c|c|c|}
\hline Geometry & Material & $\begin{array}{c}\text { Kinetic Energy } \\
(\mathbf{K J})\end{array}$ & $\begin{array}{c}\text { Weight } \\
(\mathbf{K g})\end{array}$ & $\begin{array}{c}\text { Stress } \\
(\mathbf{M P a})\end{array}$ & $\begin{array}{c}\text { Deformation } \\
(\mathbf{m m})\end{array}$ \\
\hline Perforated & Grey Cast Iron & 44 & 1130 & 47.100 & 53 \\
\hline Perforated & Carbon Steel & 48 & 1230 & 101.840 & 1 \\
\hline Perforated & Aluminium Alloy & 17 & 435 & 18.420 & 30 \\
\hline Solid & Grey Cast Iron & 45 & 1155 & 31.840 & 82 \\
\hline Solid & Carbon Steel & 49 & 1260 & 34.290 & 664 \\
\hline Solid & Aluminium Alloy & 17 & 445 & 11.880 & 7 \\
\hline Arm Type & Grey Cast Iron & 40 & 1032 & 95.430 & 297 \\
\hline Arm Type & Carbon Steel & 44 & 1126 & 104.560 & 32 \\
\hline Arm Type & Aluminium Alloy & 15 & 398 & 37.188 & 355 \\
\hline
\end{tabular}


The table above summarizes the analytical values obtained by FEA. This it can be said that the optimum design available as per the analytical data and the theoretical calculations is that of the perforated flywheel with carbon steel material for heavy duty applications and solid flywheel with aluminum alloy for light duty applications. To carry out the validation of these sets of data it is necessary to calculate the theoretical values as per the equation of stress mentioned above.

Calculating the stress as per the equation yields the value of perforated flywheel as $98.37 \mathrm{MPa}$ and that of solid flywheel is $12.76 \mathrm{MPa}$.

Now on comparing these results with that of the original flywheel, it was found that the selected set yielded better energy storing capacity. The comparison can be seen in the following table between the original flywheel and selected set among the various experimental sets carried out.

Table 3: Comparison Table

\begin{tabular}{|c|c|c|c|c|c|}
\hline Geometry & Material & $\begin{array}{c}\text { Kinetic Energy } \\
(\mathbf{K J})\end{array}$ & $\begin{array}{c}\text { Weight } \\
(\mathbf{K g})\end{array}$ & $\begin{array}{c}\text { Stress } \\
(\mathbf{M P a})\end{array}$ & $\begin{array}{c}\text { Deformation } \\
(\mathbf{m m})\end{array}$ \\
\hline Perforated & Carbon steel & 44 & 1130 & 47.10 & 53 \\
\hline Original & Grey Cast Iron & 42 & 1138 & 39.43 & 48 \\
\hline
\end{tabular}

\section{Conclusion}

Recent flywheel designs are based on analytical structures derived from simulation results. Analysis and simulation of flywheel behavior is a relatively new concept to the modelling done on flywheels. This can be of great assistance to specify the energy storage capacitance of the designed flywheel before actually developing one and thus can cut the cost expenditure if any faults are set up and can correct them.

Hence we can conclude that optimization of the flywheel is of extreme importance as it is an energy storage system with efficiency, higher compared to the other systems and possess a broad scope of application. The data obtained from analysis and theoretical data, the better design of the flywheel is selected which has energy storing capacity $0.95 \%$ more than that of the original design.

\section{References}

[1] Bai, Y., Gao, Q., Li, H., Wu, Y., \& Xuan, M. (2008). Design of composite flywheel rotor. Frontiers of Mechanical Engineering in China, 3(3), 288-292. https://doi.org/10.1007/s11465-008-0045-y

[2] Tang, C. L., Dai, X. J., Zhang, X. Z., \& Jiang, L. (2012). Rotor dynamics analysis and experiment study of the flywheel spin test system. Journal of Mechanical Science and Technology, 26(9), 2669-2677. https://doi.org/10.1007/s12206-012-0717-8

[3] Yu, Y., Wang, Y., Zhang, G., \& Sun, F. (2012). Analysis of the comprehensive physical field for a new flywheel energy storage motor/generator on ships. Journal of Marine Science and Application, 11(1), 134-142. https://doi.org/10.1007/s11804-012-1115-4

[4] Pietraszek, J. (2012). to Classical Experimental Design in the Case of Flywheel Assembly, 310-317.
[5] Patel, T. M., Bhatt, M. G., \& Patel, H. K. (2013). Analysis and validation of Eicher 11 . 10 chassis frame using Ansys, 2(2), 10-13.

[6] ESFAHANIAN, M., SAFAEI, A., NEHZATI, H., M., T., \& ESFAHANIAN, V. (2014). MATLAB-BASED MODELING, SIMULATION AND DESIGN PACKAGE FOR ELETRIC, HYDRAULIC AND FLYWHEEL HYBRID POWERTRAINS OF A CITY BUS. International Journal of ..., 15(6), 1001-1013. https://doi.org/10.1007/s12239

[7] Jiang, S., Wang, H., \& Wen, S. (2014). Flywheel energy storage system with a permanent magnet bearing and a pair of hybrid ceramic ball bearings. Journal of Mechanical Science and Technology, 28(12), 5043-5053. https://doi.org/10.1007/s12206-014$1125-\mathrm{z}$

[8] Wen, S. (2014). Analysis of maximum radial stress location of composite energy storage flywheel rotor. Archive of Applied Mechanics, 84(7), 1007-1013. https://doi.org/10.1007/s00419-014-0845-y

[9] Arakelian, V. (2016). Design of Reactionless Planar Parallel Manipulators with Inertia Flywheel or with Base-Mounted Counterrotations. Design of Reactionless Planar Parallel Manipulators with Inertia Flywheel or with Base-Mounted Counter-Rotations, 69. https://doi.org/10.1007/978-3-319-17683-3

[10] Hamzaoui, I., Bouchafaa, F., \& Talha, A. (2016). Advanced control for wind energy conversion systems with flywheel storage dedicated to improving the quality of energy. International Journal of Hydrogen Energy, 1-15. https://doi.org/10.1016/j.ijhydene.2016.06.249

[11] Rupp, A., Baier, H., Mertiny, P., \& Secanell, M. (2016). Analysis of a flywheel energy storage system for light rail transit. Energy, 107, 625-638. https://doi.org/10.1016/j.energy.2016.04.051

[12] Module, F. (1802). Flywheel, 1-6. https://en.wikipedia.org/wiki/Flywheel 